\title{
Intelligent Tourniquet System for Emergency Aid Using Wireless Network
}

\author{
Dr. K. S. Dhanalakshmi \\ Co-Authors: S. Keerthana, S. Aishwarya, R. Priyadharshini Electronics and Communication Engineering \\ Kalasalingam Academy of Research and Education, Krishnan Kovil
}

\begin{abstract}
In case of accidents during explosions and firearm injuries it is essential to use tourniquet in order to overcome the severe injuries and blood loss. There are a few essential things to consider when using a tourniquet. If it is not tightened well to arrest the blood loss, it continues and the injured person's life becomes very dangerous. If more pressure is given, and if it is not relaxed and squeezed hardly, it may cause serious issues. The purpose of this product is to produce a intelligent tourniquet system that can successfully arrest the bleeding by automatically providing the appropriate pressure to the limb, where it is affected to stop excessive bleeding in wounds. The developed system will be largely used in, first aid kits for vehicles, ambulances, emergency services for hospitals, fire trucks, first aid organizations, risky workplaces and so many civilian areas.
\end{abstract}

Keywords:- Arduino Microcontroller, Bluetooth, Pressure Motor, Seven Segment Display.

\section{INTRODUCTION}

The major reason for the death of people during accidents is loss of blood. Blood plays a vital role in human body, so it is precious to save each drop of them. All over world, people face this issue. The people who work in industries dealing with giant machines, hospitals, military and defence related jobs etc. To overcome this issue, we are coming up with this product. The product design includes first aid, tourniquet, wireless network, solar panel. This kind of accidents may occur in roads, hospitals, military etc. People who gets injured with heavy blood loss. The developed product will be widely used in ambulances, first aid kits for vehicles, emergency services for hospitals.

\section{TOURNIQUET}

A tourniquet is a tight band which is used to arrest or control the flow of blood during the accidents. A simple tourniquet can be done by a rope and a stick. The rope is modified into a loop which must be correctly placed over the damaged parts, and the stick is given into the loop. It is fixed tightly by twisting the stick. This may arrest bleeding, but side-effects or damage may occur. There are three types of tourniquets present they are : emergency tourniquets, surgical tourniquets, and rehabilitation tourniquets. In our product we are using emergency tourniquet system.

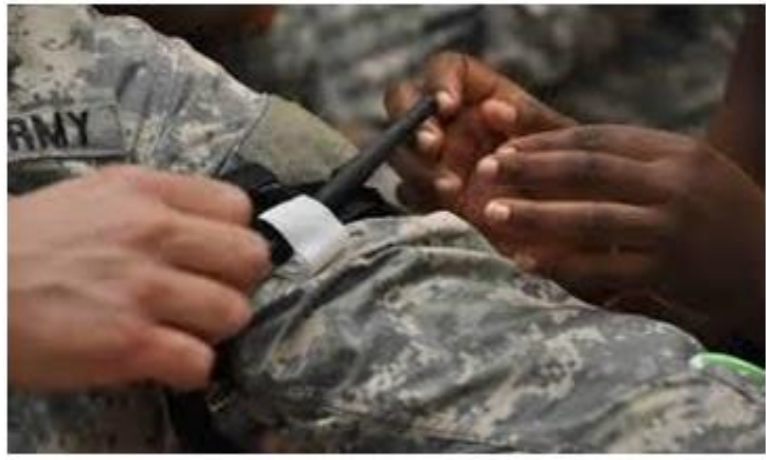

Fig 1:- Tourniquet

\section{TYPES AND PRACTICAL USE OF TOURNIQUET}

A. Types:

$>$ Surgical Tourniquet:

In this type of surgical tourniquet we use elastic ring tourniquets or Silicone ring tourniquets that are automated mechanical devices that does not need any mode of electricity or wires. These kind of tourniquet should be present after the drapes that is present on the patient.

\section{$>$ Emergency Tourniquet:}

Emergency tourniquets are cuff-like structure that is designed to arrest severe blood loss. They are draped around the limb and tightened gradually. The design and structure of emergency tourniquets allows fast response to the injured persons.

\section{$>$ Pneumatic Tourniquets:}

Pneumatic tourniquets utilize compressed gas to cuff to arrest blood loss. The regulating device on this kind of tourniquet can control the certain amount of pressure produced in cuff exerted on the limb. Now the pressure is produced by a central compressed air supply or by a electrically driven pump.

\section{B. Practical Use of Tourniquet:}

At first we find where the blood is coming from and provide steady pressure to the injured wound with hands. If the blood loss is not arrested then place a tourniquet 23inches nearer to the wound. Now the tourniquet may be applied safely. By using the tourniquet we can control the blood pressure and monitor it. In case still the bleeding does not get arrested then we place a second tourniquet nearer the wound. 


\section{APPLICATION OF TOURNIQUET}

Tourniquets must be used when major injuries are occurred and standard controlled tourniquets will be harmless to the patient.

Tourniquets should be placed nearer to the injury to control blood loss.
Once a tourniquet is fixed in a place we must not remove that. Although when the person feels uncomfortable due to its presence.

Significant pressure is needed to be applied to the tourniquet till the bleeding gets arrested.

$>$ Once when the tourniquet is placed the timing must be noted down.

\section{BLOCK DIAGRAM}

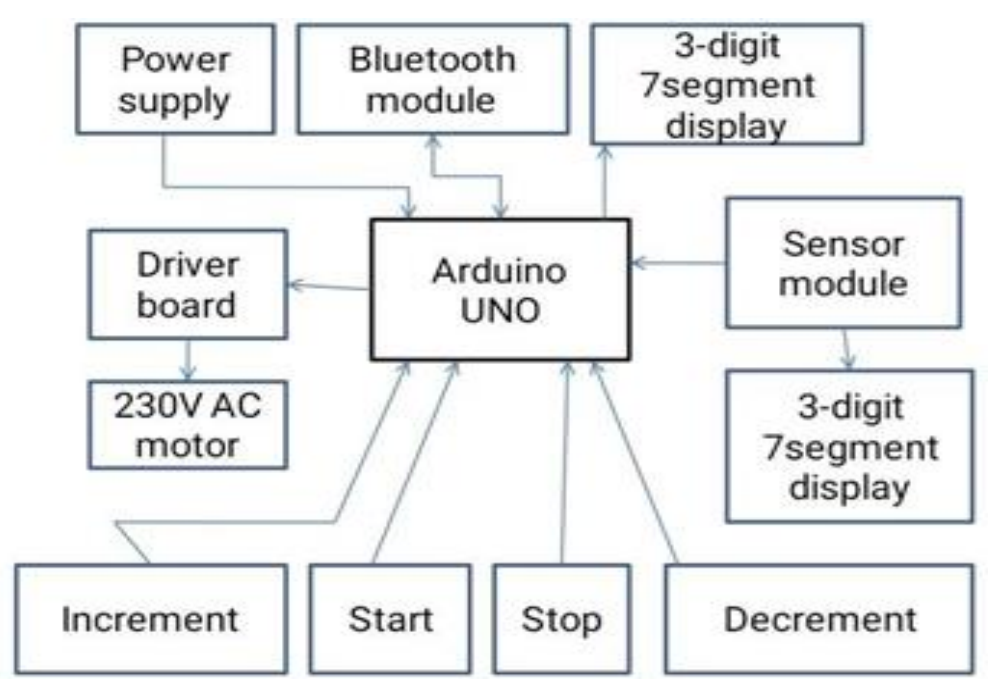

Fig 2:- Block diagram

\section{WORKING}

This system includes components like arduino,7 segment display, driver motor, pressure cuff, pressure motor, $5 \mathrm{v}$ power supply. Firstly we give power supply to start the device using start button. Once the device is turned on the driver motor will produce $230 \mathrm{~V}$ then the AC motor will suppress the air to fill the cuff with the air. Here we also use increment and decrement buttons to setup the pressure range and it will be displayed on the 7 segment display. Also we can alter the pressure rate by using those buttons. Now we use a sensor to sense the range of the pressure and display the readings in the 3 digit 7 segment display. If the pressure range is exceeded we can reduce it by using the decrement button. If the range is decreased we use the increment button. We are using Bluetooth as the wireless medium to on and off the entire device. If the arduino produces $5 \mathrm{~V}$ ground data $230 \mathrm{~V}$ will get on. If there is no voltage present in the arduino then the $230 \mathrm{~V}$ cannot be turned on. By using this type of methodology the death rate during accidents is decreased due to the fast access provided by the network. For developing this product we use proteus 8 software for stimulating the product . Embedded $\mathrm{C}$ program is incorporated in this product. If there is no electricity present while accessing the device we use solar panels to provide the backup for the device.

\section{ARDUINO MICROCONTROLLER}

Arduino is a microcontroller device which is used to connect the hardware and software components together. We can use $\mathrm{C}$ and $\mathrm{C}++$ programming languages and embedded $\mathrm{C}$ to develop the coding part. It use a various types of microprocessors and controllers. These boards are given with many digital and analog input or output pins that might be used to connect various types of breadboards and circuits. There are many ranges in the arduino series to develop different kinds of products.

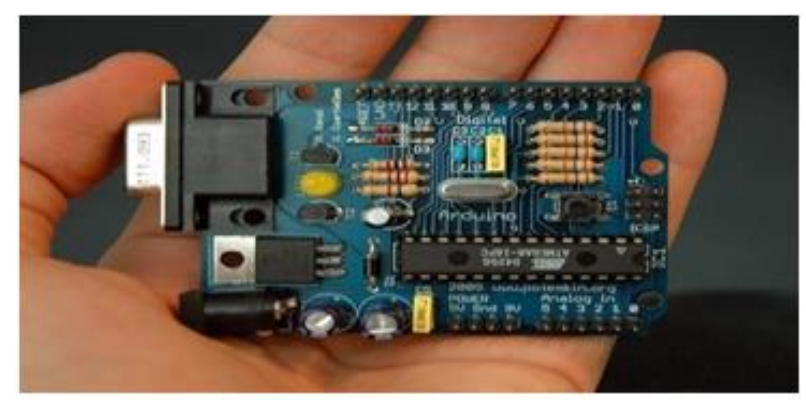

Fig 3:- Arduino

\section{USAGE OF WIRELESS NETWORK}

The wireless local-area network (WLAN) utilizes radio propagations to connect systems such as laptops, play stations and mobile phones to access the Internet and its applications. And when you connect to a Wi-Fi at public network sector you're connected to that business type of wireless network. 


\section{Mobility}

In wired network devices the people tend to stick on to a place for accessing the network. Whereas in wireless we can access in from any place.

\section{Convenience}

In wireless we can access the network availability from any place within the certain coverage or from any WiFi.

\section{$>$ Easy Setup}

Usage of cables are minimized so the speed for accessing the network is increased.

\section{$>$ Security}

Wireless provides high security such as robust security protection.

\section{$>$ Productivity}

Using wireless network it is accessible for people to be more collaborative to each other when they are working in an industry or an organization.

$>$ Cost

It is more cost effective when compared to the wired networks.

\section{SOLAR PANEL}

The solar panel is an arrangement of solar cells that can change light source into electricity. And By joining the capacity of various solar panels, a part of a electricity requirement can be utilized. At this time, depending on the various kinds of panel, 6 to $20 \%$ of the light source can be changed into electricity. This is called as "output" of the solar panel. The technology is subsequently being developed, and the output should enhance further. By using solar panels we can change sunlight, into electricity. The solar panel produces direct current. We can use this current in the home or office, it must be changed to alternating power source of $230 \mathrm{~V}$. This can be done by the inverter or converter.

\section{HIGHLIGHTS OF THIS SYSTEM}

\section{A. Merits}

$>$ Due to wireless communication system long distance connectivity is possible.

$>$ This product is cost efficient.

Death rate during accidents are decreased.

Speed is high.

\section{B. Demerits}

If there is no awareness regarding the practical usage of tourniquet then the consequences will be worst.

\section{CONCLUSION}

In the existing product they use wired system. So if there is any hardware fault or power loss the total system will get collapsed. To avoid such kind of incidents we use wireless communicating network and also we are using solar panel to provide power backup to the device in case of absence of the electricity.

\section{REFERENCES}

[1]. Budak, E. İ. (2017). Development of Tourniquet System For Military Use (master thesis). TOBB University of Economics and Technology, Ankara, TURKEY.

[2]. Unlu A, Petrone P, Guvenc I, Kaymak S, Arslan G, K.aya E, Y1lmaz S, Cetinkaya RA, Ege T, Ozer MT, Kilic S. Combat application tourniquet (CAT) eradicates popliteal pulses effectively by correcting the windlass turn degrees: a trial on 145 participants. Eur J Trauma Emerg Surg. 2017 Oct;43(5):605-609.

[3]. Role 2 military hospitals: results of a new trauma care concept on 170 casualties. Ünlü A, Cetinkaya RA, Ege T, Ozmen P, Hurmeric V, Ozer MT, Petrone P. Eur J Trauma Emerg Surg. 2015 Apr;41(2):149-55.

[4]. Unlu, A., vd. (2014). An evaluation of combat application tourniquets on training military personnel: changes in application times and success rates in three successive phases, Journal of the Royal Army Medical Corps jramc-2014.

[5]. Kragh J., J. F., vd. (2008). Practical use of emergency tourniquets to stop bleeding in major limb trauma, Journal of Trauma and Acute Care Surgery, 64.2 S38S50.

[6]. Kragh J., J. F., Walters, T. J., Baer, D. G., Fox, C. J., Wade, C. E., Salinas, J. \& Holcomb, J. B. (2008). Practical use of emergency tourniquets to stop bleeding in major limb trauma. Journal of Trauma and Acute Care Surgery, 64(2), S38-S50. 